\title{
Novel nonpharmacologic approaches for stroke prevention in atrial fibrillation: results from clinical trials
}

REVIEW

This article was published in the following Dove Press journal:

Medical Devices: Evidence and Research

29 January 2015

Number of times this article has been viewed

\section{Riccardo Proietti ${ }^{1,2}$ \\ Jacqueline Joza' \\ Andrea Arensi ${ }^{2}$ \\ Michael Levi' \\ Vincenzo Russo 3 \\ Apostolos Tzikas ${ }^{4}$ \\ Paolo Danna ${ }^{2}$ \\ Antonio Sagone ${ }^{2}$ \\ Maurizio Viecca ${ }^{2}$ \\ Vidal Essebag 1,5}

'McGill University Health Center, Montreal, QC, Canada; ${ }^{2}$ Cardiology Department, Luigi Sacco Hospital, Milano, Italy; ${ }^{3}$ Cardiology Department, Second University of Naples, Monaldi Hospital, Naples, Italy; ${ }^{4}$ Interbalkan

European Medical Centre,

Thessaloniki, Greece; ${ }^{5} \mathrm{Hôpital}$

Sacré-Coeur de Montréal, Montreal,

QC, Canada
Correspondence: Vidal Essebag McGill University, McGill University Health Centre, 1650 Cedar Ave, Room E5-200, Montreal, H3G IA4

Quebec, Canada

$\mathrm{Tel}+$ I 5 |4 934 I934 ext 43।57

$\mathrm{Fax}+$ I 5 I49348377

Email vidal.essebag@mcgill.ca
Abstract: Atrial fibrillation (AF), the most common cardiac arrhythmia, confers a 5-fold risk of stroke that increases to 17-fold when associated with mitral stenosis. At this time, the most effective long-term solution to protect patients from stroke and thromboembolism is oral anticoagulation, either with vitamin $\mathrm{K}$ antagonists (VKAs) or a novel oral anticoagulant (NOAC) Despite the significant benefits they confer, both VKAs and NOACs are underused because of their increased potential for bleeding, and VKAs are underused because of their narrow therapeutic range, need for regular international normalized ratio checks, and interactions with food or medications. In patients with nonvalvular AF, approximately $90 \%$ of strokes originate from the left atrial appendage (LAA); in patients with rheumatic mitral valve disease, many patients $(60 \%)$ have strokes that originate from the left atrium itself. Surgical LAA amputation or closure, although widely used to reduce stroke risk in association with cardiac surgery, is not currently performed as a stand-alone operation for stroke risk reduction because of its invasiveness. Percutaneous LAA closure, as an alternative to anticoagulation, has been increasingly used during the last decade in an effort to reduce stroke risk in nonvalvular AF. Several devices have been introduced during this time, of which one has demonstrated noninferiority compared with warfarin in a randomized controlled trial. This review describes the available technologies for percutaneous LAA closure, as well as a summary of the published trials concerning their safety and efficacy in reducing stroke risk in AF.

Keywords: left atrial appendage closure, atrial fibrillation, CHADS

\section{Introduction}

Atrial fibrillation (AF) is the most common cardiac arrhythmia, affecting $1 \%-2 \%$ of the general population, ${ }^{1}$ although this may be an underestimate. Studies assessing silent AF using modern implantable rhythm monitoring devices suggest that up to $50 \%-60 \%$ of patients older than 65 years may have unsuspected episodes of $\mathrm{AF}^{2,3}$ The relevance of these data is best understood in view of the increased mortality and morbidity associated with AF: nonvalvular AF confers a fivefold risk of stroke, ${ }^{1}$ which increases to 17 -fold in patients with mitral stenosis. ${ }^{4}$

At the present time, vitamin $\mathrm{K}$ antagonists (VKAs) remain the mainstay for stroke prevention in AF. In a meta-analysis by Hart et al, ${ }^{5}$ a $64 \%$ reduction in overall stroke risk was observed in patients using adjusted-dose VKAs (the reduction increased to $68 \%$ when only ischemic strokes were considered). Despite such strong evidence, warfarin is still underused because of its associated bleeding risk, need for regular monitoring, narrow therapeutic range, and common interactions with other medications as well as food. ${ }^{4,6}$ In certain subgroups of patients, or when bleeding risk is elevated, 
acetylsalicylic acid (ASA), alone or in combination with clopidogrel, may be considered as an alternative to VKAs. ${ }^{7}$ However, antiplatelet agents are inferior to VKAs for stroke prevention and may be associated with similar bleeding risk, particularly in elderly patients. ${ }^{5,7-10}$

As an alternative to VKAs, novel oral anticoagulant agents (NOACs) have been increasingly used. The RE-LY (Randomized Evaluation of Long-term Anticoagulant Therapy) trial ${ }^{11}$ (dabigatran 110 or $150 \mathrm{mg}$ twice daily), the ROCKET-AF (Rivaroxaban Once-Daily, Oral, Direct Factor Xa Inhibition Compared With Vitamin K Antagonism for Prevention of Stroke and Embolism Trial in Atrial Fibrillation) ${ }^{12}$ trial (rivaroxaban $20 \mathrm{mg}$ once daily), the ARISTOTLE (Apixaban for the Prevention of Stroke in Subjects With Atrial Fibrillation) ${ }^{13}$ trial (apixaban $5 \mathrm{mg}$ twice daily), and the ENGAGE AF TIMI 48 (Effective Anticoagulation with Factor Xa Next Generation in Atrial Fibrillation-Thrombolysis in Myocardial Infarction 48) ${ }^{14}$ trial (edoxaban 60 or $30 \mathrm{mg}$ once daily), using dose-adjusted warfarin as standard-of-care control, showed noninferiority or superiority for the efficacy outcome of combined ischemic stroke and systemic embolism in patients with nonvalvular AF. However, the composite outcome of major bleeding does not differ substantially from warfarin. ${ }^{15-18}$

The exact mechanism of thrombus formation in AFrelated strokes, although not yet fully understood, involves the presence of endocardial injury, hypercoagulability, and blood stasis in the atria. ${ }^{3}$ The latter seems to play a pivotal role; in fact, the failure of the left atrium to effectively contract results in atrial stretch and dilation, favoring thrombus formation. ${ }^{3}$ Approximately $75 \%$ of embolic events associated with $\mathrm{AF}$ result from atrial thrombosis. ${ }^{19} \mathrm{~A}$ review of autopsy, echocardiographic, and operative reports demonstrate that atrial thrombi can be identified in the left atrial appendage (LAA) in $91 \%$ of nonvalvular AF cases and $57 \%$ of rheumatic $\mathrm{AF}$ cases. ${ }^{20} \mathrm{AF}$ is associated with a systemic prothrombotic state characterized by endothelial dysfunction and platelet activation. ${ }^{21}$ There are several anatomical features and physiological characteristics that explain the pivotal role played by the LAA as a major site of thrombus formation and source of thromboembolic stroke. First, the wall of the LAA has numerous trabeculae (pectinate muscles), forming crypts that can harbor blood clots. These features differentiate the LAA from the left atrium that has a smooth wall. A different embryologic origin explains this different characteristic. Douglas et $\mathrm{al}^{22}$ described that the LAA originates by the incorporation of the left pulmonary vein in the body of the left atrium. Second, the macroscopic anatomy of the LAA is complex and highly variable, with a long, tubular, and often multilobed body extending over the atrioventricular groove and left ventricular surface. Recently, a correlation between the morphology of the LAA and embolic risk has been described. ${ }^{23}$ The LAA ostium is usually oval-shaped and located anterior and inferior to the left superior pulmonary vein.

Third, the LAA is also more distensible than the left atrium itself and can receive a large volume of blood when the pressure in the left atrium is high. Thus, the LAA acts as a decompression chamber of the left atrium. Fourth, a reduction in stroke volume and cardiac output has been described after removal of the LAA. ${ }^{24,25}$ Fifth, anatomically, the LAA lies superior and anterior to the left ventricle in close contact with the left ventricular wall. As a consequence, changes in the left ventricular volume and pressure can be transmitted to the LAA wall, which affects blood flow through the LAA.

Finally, the LAA plays an important physiologic function in regulating intravascular volume through the release of atrial natriuretic factor. Of note, almost $30 \%$ of atrial natriuretic factor is stored in the LAA.

Since 1949, surgical LAA exclusion has been performed to reduce stroke risk in cardiac valve surgery in patients with $\mathrm{AF}^{26}$ but this procedure is too invasive to be used as a standalone operation in patients who do not have any other concurrent indication to undergo cardiac surgery. Percutaneous LAA closure is a relatively new procedure that obviates the need for sternotomy and cardiopulmonary bypass and is an attractive alternative to chronic anticoagulation with VKAs or NOACs in reducing stroke risk in nonvalvular AF. Exclusion of the LAA cavity from the atrium can be achieved with devices that are positioned at the neck of the LAA by either an endovascular or epicardial approach (Table 1).

This review describes the current technologies used in percutaneous LAA closure (Table 2), as well as a summary of the published trials concerning their efficacy in reducing stroke risk in $\mathrm{AF}$.

\section{Percutaneous LAA closure: endovascular approach}

The PLAATO (Percutaneous Left Atrial Appendage Transcatheter Occlusion) device (Appriva Medical, Inc., Sunnyvale, CA, USA) was the first LAA occlusion device designed; however, as of 2007, it is no longer in production. ${ }^{27}$ It consists of a self-expanding nitinol cage covered by an impermeable polymeric membrane. Three rows of anchors along the struts help stabilize the device in the LAA. The diameters of the PLAATO device range between 15 and 
Table I Characteristics and results of the main clinical trials in left atrial appendage closure, including safety and efficacy

\begin{tabular}{|c|c|c|c|c|c|}
\hline Device and study & Patients, $\mathrm{n}$ & $\begin{array}{l}\text { Follow-up, } \\
\text { months }\end{array}$ & $\begin{array}{l}\text { Procedural } \\
\text { success, } \%\end{array}$ & Procedural complications, $\%$ & $\begin{array}{l}\text { Incidence of stroke } \\
\text { at follow-up, \% }\end{array}$ \\
\hline \multicolumn{6}{|l|}{ Percutaneous Left Atrial } \\
\hline \multicolumn{6}{|l|}{ Appendage Transcatheter } \\
\hline \multicolumn{6}{|l|}{ Occlusion } \\
\hline Sievert et $\mathrm{a}^{29}$ & 15 & I & 100 & $6.7 \%$ nonfatal hemopericardium & 0 \\
\hline Ostermayer et $\mathrm{al}^{30}$ & 111 & 9.8 & 97.3 & $\begin{array}{l}0.9 \% \text { cardiac tamponade, } 0.9 \% \\
\text { femoral artery perforation, } 4.5 \% \\
\text { nonfatal hemopericardium }\end{array}$ & 2.2 \\
\hline Bayard et $\mathrm{al}^{27}$ & 291 & 12 & NS & $\begin{array}{l}3.4 \% \text { cardiac tamponade, } 0.3 \% \\
\text { death }\end{array}$ & 3 \\
\hline Block et al ${ }^{34}$ & 64 & 60 & 95.3 & I.5\% cardiac tamponade & 3.8 \\
\hline Park et $\mathrm{al}^{35}$ & 73 & 24 & 97.3 & $\begin{array}{l}\text { I.4\% death caused by device } \\
\text { embolization, I.4\% nonfatal } \\
\text { hemopericardium, } 1.4 \% \\
\text { periprocedural stroke }\end{array}$ & 0 \\
\hline Ussia et $\mathrm{al}^{36}$ & 20 & 40 & 90 & $5 \%$ nonfatal hemopericardium & 0 \\
\hline Bayard et $\mathrm{al}^{32}$ & 180 & 9.6 & 90 & $\begin{array}{l}3.3 \% \text { nonfatal cardiac tamponade, } \\
0.6 \% \text { device embolization, I.I\% } \\
\text { death }\end{array}$ & 2.3 \\
\hline \multicolumn{6}{|l|}{ Watchman } \\
\hline Sick et $\mathrm{al}^{20}$ & 75 & 24 & 88 & $\begin{array}{l}2.6 \% \text { cardiac tamponade, } 4 \% \\
\text { hemopericardium, } 2.6 \% \text { device } \\
\text { embolization, } 5.3 \% \text { thrombus } \\
\text { formation on device }\end{array}$ & 0 \\
\hline Holmes et a $\left.\right|^{38}$ & 707 & 18 & 91 & $\begin{array}{l}4.9 \% \text { hemopericardium, } 0.7 \% \\
\text { device embolization, } 3.7 \% \text { thrombus } \\
\text { formation on device }\end{array}$ & 2.3 \\
\hline \multicolumn{6}{|l|}{ Amplatzer } \\
\hline \multicolumn{6}{|l|}{ Cardiac plug } \\
\hline Meier et al ${ }^{70}$ & 16 & 4 & 93.75 & $6.25 \%$ device embolization, $5 \%$ & 0 \\
\hline Lam et al ${ }^{48}$ & 20 & 12 & 95 & $\begin{array}{l}\text { coronary air embolism, } 5 \% \text { esophageal } \\
\text { injury resulting from TEE }\end{array}$ & 0 \\
\hline Lopez-Minguez et al ${ }^{49}$ & 35 & 21 & 97.14 & $\begin{array}{l}2.8 \% \text { arteriovenous fistulas, } 2.8 \% \\
\text { of gastrointestinal bleed, } 14.28 \% \\
\text { thrombus formation on device }\end{array}$ & 2.8 \\
\hline Park et a $\left.\right|^{47}$ & 137 & NS & 96 & $\begin{array}{l}3.6 \% \text { hemopericardium, } 1.4 \% \\
\text { device embolization }\end{array}$ & 2.2 \\
\hline \multicolumn{6}{|l|}{ Amulet } \\
\hline Freixa et $\mathrm{al}^{52}$ & 25 & 3 & 96 & None reported & 0 \\
\hline \multicolumn{6}{|l|}{ LARIAT $^{\circledR}$} \\
\hline Bartus et $\mathrm{al}^{59}$ & 13 & NS & 92.3 & None reported & 0 \\
\hline Bartus et $a^{60}$ & 89 & 12 & 95 & $3.3 \%$ access related & 0 \\
\hline Stone et $\mathrm{a}^{61}$ & 27 & 4 & 92.6 & $\begin{array}{l}3.7 \% \text { left atrial appendage } \\
\text { perforation, } 11.1 \% \text { pericarditis }\end{array}$ & 3.7 \\
\hline
\end{tabular}

Abbreviations: NS, not stated; TEE, trans esophageal echocardiogram.

$35 \mathrm{~mm}$, and it is $20 \%-40 \%$ larger than the LAA ostium. It is deployed through a catheter introduced via the femoral vein and is advanced from the right to the left atrium by transseptal puncture. During the months after the procedure, the device endothelializes with proliferation of a new layer of neointima, starting at the edges of the device. The neointimal growth is continued with the atrial wall and is usually tighter at the border of the implant surface and looser at the center. ${ }^{28}$ The time span for a complete sealing of the device in the atrial wall is usually around 3 months. However, the amount of time an antithrombotic agent should be administered to avoid thrombotic complications is highly debated in the literature. After PLAATO implantation, lifelong ASA administration is, in general, recommended.

In 2002, Sievert et $\mathrm{al}^{29}$ published a pilot study evaluating the feasibility and safety of the PLAATO device. Fifteen patients underwent a successful procedure, although one patient required a second attempt after sustaining hemopericardium. Subsequent studies on the PLAATO device focused on the effectiveness of percutaneous 
Table 2 Technical characteristics of the devices

\begin{tabular}{|c|c|c|c|c|}
\hline Device & Deployment & Sizes & Device selection & Anticoagulation \\
\hline Percutaneous Left Atrial Appendage & Endovascular & $15-32 \mathrm{~mm}$ & $20 \%-40 \%$ larger than the left & No \\
\hline Transcatheter Occlusion & & & atrial appendage ostium diameter & \\
\hline Watchman & Endovascular & $21,24,27$, and $30 \mathrm{~mm}$ & $\begin{array}{l}10 \%-20 \% \text { larger than the left } \\
\text { atrial appendage ostium diameter }\end{array}$ & Yes (45 days) \\
\hline Amplatzer cardiac plug & Endovascular & $16-30 \mathrm{~mm}$ & $\begin{array}{l}10 \%-20 \% \text { larger than the left } \\
\text { atrial appendage orifice }\end{array}$ & No \\
\hline Amulet & Endovascular & $16-34 \mathrm{~mm}$ & $\begin{array}{l}3-6 \mathrm{~mm} \text { larger than left atrial } \\
\text { appendage ostium }\end{array}$ & No \\
\hline Lariat & Endo-epicardial & $\mathrm{W} 40 \times \mathrm{H} 20 \times \mathrm{L} 70 \mathrm{~mm}$ & N/A & No \\
\hline
\end{tabular}

Abbreviations: N/A, not available; $W$, width; $H$, height; $L$, length.

LAA occlusion in preventing strokes. The International Multi-Center Feasibility trial ${ }^{30}$ enrolled 111 patients with contraindication to anticoagulation therapy. The success rate of implantation was $97.3 \%$; reasons for unsuccessful implantation were thrombus in the LAA in one patient, perforation of the femoral artery during femoral puncture in another patient, and cardiac tamponade in the third patient. Pericardial effusion or hemopericardium occurred in $4.5 \%$ of patients. During a 9.8 month follow-up, a $65 \%$ reduction in stroke rate was observed compared with the expected stroke risk, as calculated using the $\mathrm{CHADS}_{2}$ score (representing congestive heart failure, hypertension, age, diabetes mellitus, and stroke, the $\mathrm{CHADS}_{2}$ score is a clinical prediction rule widely used for estimating the risk of stroke in patients with nonvalvular AF). It is worth emphasizing that the authors excluded three transient ischemic attacks (TIAs) from the number of strokes and justify this on the basis that the $\mathrm{CHADS}_{2}$ score was elaborated to calculate the risk for strokes and not for TIAs. ${ }^{31}$ Residual peridevice leaks were observed not uncommonly by fluoroscopy or echocardiogram, and LAA occlusion was defined as absent, trace, or a mild leak on the basis of these imaging modalities. This is a point of interest that has been the focus of critique not only for the PLAATO device but also for the newer devices as well and will be discussed later on in this review.

Bayard et $\mathrm{al}^{32}$ report their experience with the PLAATO device in 180 patients. The LAA closure procedure was successful in $162(90 \%)$ but failed in $18(10 \%)$ patients because of anatomic characteristics of the LAA (14 cases), impossibility of accessing the LAA ( 2 cases), complications during transseptal puncture (1 case), and device instability (1 case). Two unexplained deaths occurred within 24 hours of the procedure. Six cases of cardiac tamponade were registered, and two required surgical drainage. One PLAATO device embolized requiring retrieval by snaring catheter, and a larger device was successfully implanted in the same procedure. One case of device thrombus documented at 1 month eventually resolved with low-molecular-weight heparin. The observed stroke rate was $2.3 \%$, correlating to a $65 \%$ reduction compared with a $\mathrm{CHADS}_{2}$-based estimate.

A composite of the International Multi-Center Feasibility trial and the European-only PLAATO Registry Study, ${ }^{27}$ including almost 300 patients, demonstrated a relative reduction of stroke rate of 54\% with PLAATO compared with the stroke rate in a historic control group, using the $\mathrm{CHADS}_{2} \cdot{ }^{33}$ In this registry, thrombus formation was reported in $1 \%$ of cases within the first 6 months and was not associated with any neurological events.

Long-term follow-up of the PLAATO device is reported in three trials. Block et $\mathrm{al}^{34}$ reported a mean 3.75 year follow-up of 64 patients. The observed annual stroke rate was $3.8 \%$, which correlated with a $42 \%$ reduction compared with the $\mathrm{CHADS}_{2}$-expected risk. Park et al ${ }^{35}$ reported a 2 year follow-up in 73 patients. The success rate of LAA occlusion was $97.3 \%$, and procedural complications included one death resulting from device embolization, one pericardial effusion, and one periprocedural stroke. During follow-up, no strokes were observed, diverging from an expected incidence of seven events. Finally, Ussia et a ${ }^{36}$ successfully implanted the PLAATO device for LAA occlusion in 18 of 20 patients. One pericardial effusion occurred, requiring pericardiocentesis. No strokes were observed during a 40-month follow-up period.

Nevertheless, financial problems of the manufacturer and a significant rate of adverse events, as mentioned earlier, led to discontinuation of the device in 2006. ${ }^{37}$

The Watchman LAA System (Figure 1) became available in 2002. Similar to the PLAATO device, it is a nitinol-cage device with a row of fixation barbs around the surface, but it differs from the PLAATO device in that its polymeric membrane is permeable. The Watchman LAA closure device is available in five different sizes, ranging from 21 to $33 \mathrm{~mm}$, and is usually selected $10 \%-20 \%$ larger than the LAA ostium. 

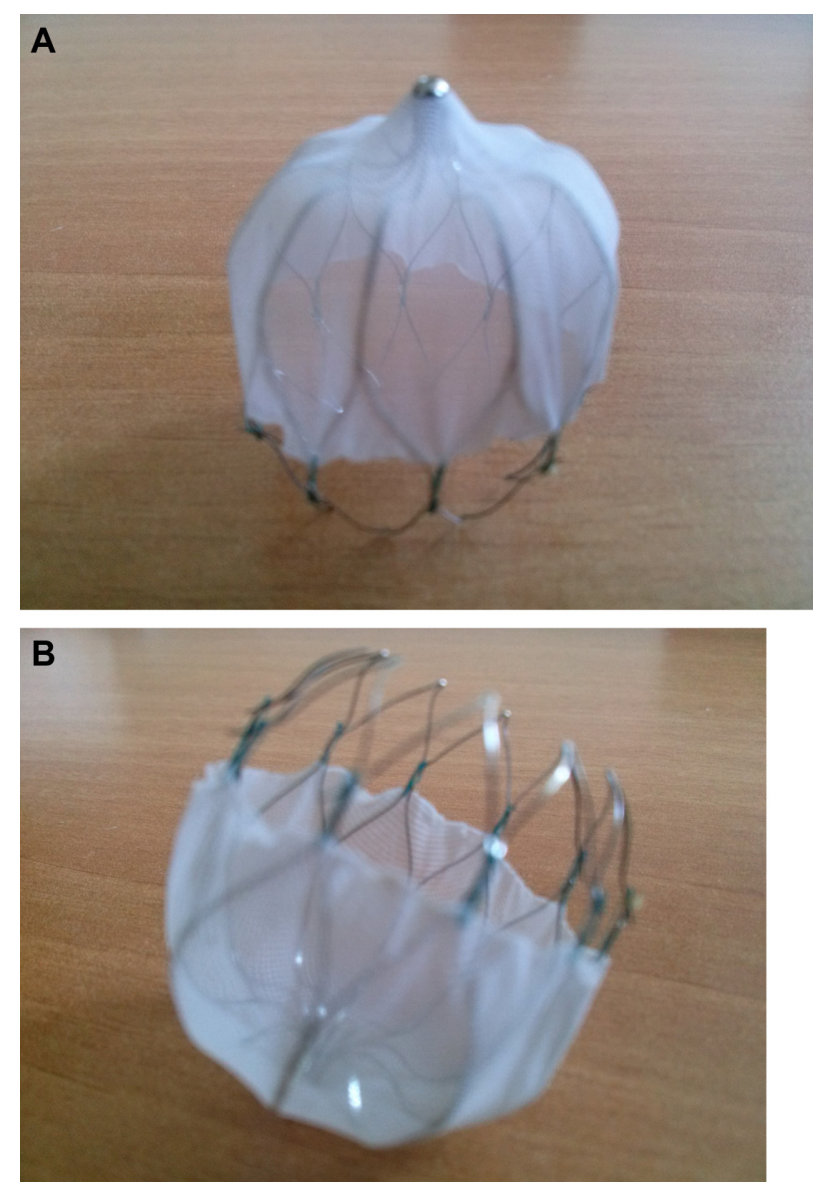

Figure I Watchman left atrial appendage system from above (A) and below (B).

The PROTECT AF (Watchman Left Atrial Appendage System for Embolic Protection in Patients with Atrial Fibrillation) trial, ${ }^{38}$ published in 2009 , was a randomized controlled trial that involved the randomization of $707 \mathrm{AF}$ patients with at least one stroke risk factor to the Watchman device versus warfarin in a 2:1 fashion. The device was found to be noninferior to warfarin for the combined end-point of stroke, systemic embolism, and cardiovascular death. The success rate for implantation was $91 \%$, with procedural complications including pericardial effusions requiring intervention in $4.8 \%$ and device embolization in $0.6 \%$. Thrombus formation on the device was observed in $3.7 \%$ of cases at 6 weeks postprocedure.

Those receiving the device were treated with warfarin for approximately 45 days, followed by clopidogrel for 4.5 months, and then lifelong ASA. Because only $30 \%$ of patients had been followed for more than 2 years in the original publication of the PROTECT AF trial, the success of the device could have been attributed in part to the ongoing anticoagulation that was received. However, a recently published 2.3 year ( \pm 1.1 years) follow-up study of PROTECT
AF confirmed the noninferiority of the Watchman device. ${ }^{39}$ There were no statistically significant differences detected in individual comparisons between the two groups; however, the confidence interval was wide $(95 \%$ confidence interval, 0.36-1.76). ${ }^{38}$ The device group exhibited more ischemic strokes, but less cardiovascular death and less hemorrhagic stroke. Of note, all patients in the control group received warfarin (time in therapeutic international normalized ratio range was $66 \%$ ), with $34 \%$ of control patients having had interrupted anticoagulation at some point for various reasons. The primary safety endpoint, which included both procedure-related events (including pericardial effusion requiring intervention of hospitalization, procedure-related stroke, or device embolization) and major bleeding (intracranial bleeding or gastrointestinal bleeding requiring transfusion) was higher in the device group (5.5\% per year) than the control group (3.6\% per year), for a risk ratio of 1.53 (95\% confidence interval, 0.95-2.70). Importantly, patients with a previous history of stroke or TIA appeared to receive sustained benefit from the device that was at least as good as warfarin therapy. ${ }^{39}$

Peridevice leaks with the Watchman device detected by transesophageal echocardiography were common (up to $30 \%$ at 12 months), ${ }^{40}$ although a recent retrospective analysis of the PROTECT AF trial showed no effect on the effectiveness of the device. ${ }^{41}$ LAA closure with the Watchman device also resulted in improved quality of life. ${ }^{4}$

Gangireddy et $\mathrm{al}^{43}$ estimated the net clinical benefit (NCB) of percutaneous LAA closure in a post hoc analysis of outcomes among $707 \mathrm{AF}$ patients in the PROTECT AF trial and 566 in the Continued Access registry who were undergoing LAA closure with the Watchman device compared with anticoagulation with a VKA. Outcomes were ischemic stroke, intracranial hemorrhage, major bleeding, pericardial effusion, and death. The NCB was calculated as the sum of annualized rates of these outcomes after intervention minus rates when receiving warfarin. The NCB initially favored anticoagulation, but 6-9 months after the procedure, the NCB then favored the device-based intervention, driven mainly by reductions in intracranial hemorrhage and death in patients undergoing LAA closure. Importantly, operator experience significantly affected the safety and efficacy end-points of the intervention: the incidence of procedure-related events was considerably lower in the nonrandomized Continued Access registry that followed the PROTECT AF trial, with the NCB clearly favoring intervention in the registry. As expected, the highest net clinical benefit was observed for patients with high $\mathrm{CHADS}_{2}$ scores. 
Sick et $\mathrm{al}^{20}$ performed 75 Watchman device implantations, of which $66(88 \%)$ were successful. No strokes were observed during a 24-month follow-up. Two cardiac tamponades were reported as well as three pericardial effusions not requiring intervention. Thrombus formation in four patients, in addition to two device embolizations, was reported.

Originally, VKA therapy was required for 45 days after LAA closure with the Watchman device, followed by dualantiplatelet therapy for up to 6 months, followed by ASA alone. The ASAP Study (ASA Plavix Feasibility Study With Watchman Left Atrial Appendage Closure Technology), presented in 2012, was a feasibility study designed to evaluate whether the Watchman device could be used for patients who were unable to take warfarin. In this nonrandomized study enrolling 150 patients with an average $\mathrm{CHADS}_{2}$ score of 2.8 who had a contraindication to anticoagulation, patients were treated with both ASA and clopidogrel for 6 months after implantation instead of the standard warfarin. During follow-up, three ischemic strokes were observed, corresponding to 1.7 events per 100 patient-years (a 77\% reduction in the expected stroke rate based on the $\mathrm{CHADS}_{2}$ score estimate). In fact, despite not using warfarin, the event rate was lower than in the PROTECT AF study (2.2 strokes per 100 patient-years). ${ }^{44}$ These new data permitted the use of the Watchman device in patients with nonvalvular AF and contraindications to VKA therapy.

It should be noted that LAA closure does not eliminate the need of warfarin. An editorial published by Whitlock et al ${ }^{21}$ showed that patients undergoing LAA closure still had a considerable incidence of stroke in the randomized and nonrandomized control trials at follow-up. Specifically alluding to the PROTECT AF trial, incidence of strokes at follow up were $50 \%$ more in the device group compared with in the warfarin group, at $3.0 \%$ versus $2.0 \% .{ }^{45}$ One can argue the need for anticoagulation or antiplatelet therapy added to LAA closure indefinitely.

Last, the PREVAIL (Watchman LAA Closure Device in Patients With Atrial Fibrillation Versus Long Term Warfarin Therapy) study ${ }^{46}$ was a randomized controlled trial including 269 patients in the Watchman LAA closure group compared with 138 patients in the warfarin group. Although the study group (Watchman) did not achieve the prespecified criteria for noninferiority at 18 months' follow-up compared with the control group (Warfarin), the overall periprocedural early events were lower than in the PROTECT AF trial, at $2.2 \%$ versus $4.9 \%$, respectively. Overall, adverse events in the PREVAIL trial were significantly lower than in the PROTECT AF trial, at $4.2 \%$ versus $8.7 \%(P=0.004)$.

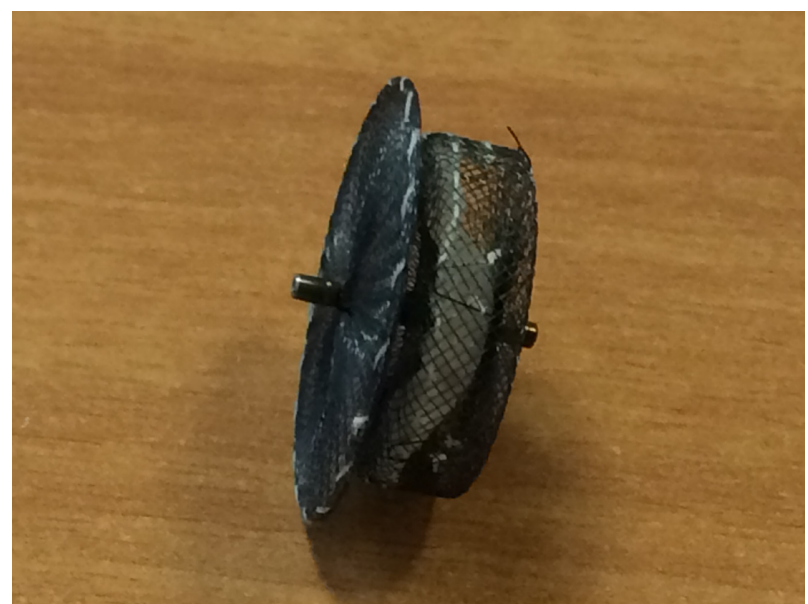

Figure 2 Amplatzer cardiac plug.

Notes: Note the different shape compared with the Watchman device. In the Amplatzer cardiac plug device, the fixing lobe is separated, allowing the disc to fully cover the left atrial appendage ostium.

The Amplatzer cardiac plug (ACP; Figures 2 and 3) is a nitinol device. Unlike the PLAATO and Watchman devices, the ACP consists of two parts, the lobe and the disc, which are connected by a central waist. Twelve stabilizing wires are equally displaced around the main disc and contribute to device retention and stabilization inside the LAA. The sizes of the lobe range from 16 to $30 \mathrm{~mm}$, and it is designed to hug the inner wall of the LAA. The lobe enters into the LAA neck with a depth of $10 \mathrm{~mm}$ or more, anchoring the device, whereas the disc covers the LAA orifice, thereby occluding it. After the procedure, 1 month of double antiplatelet

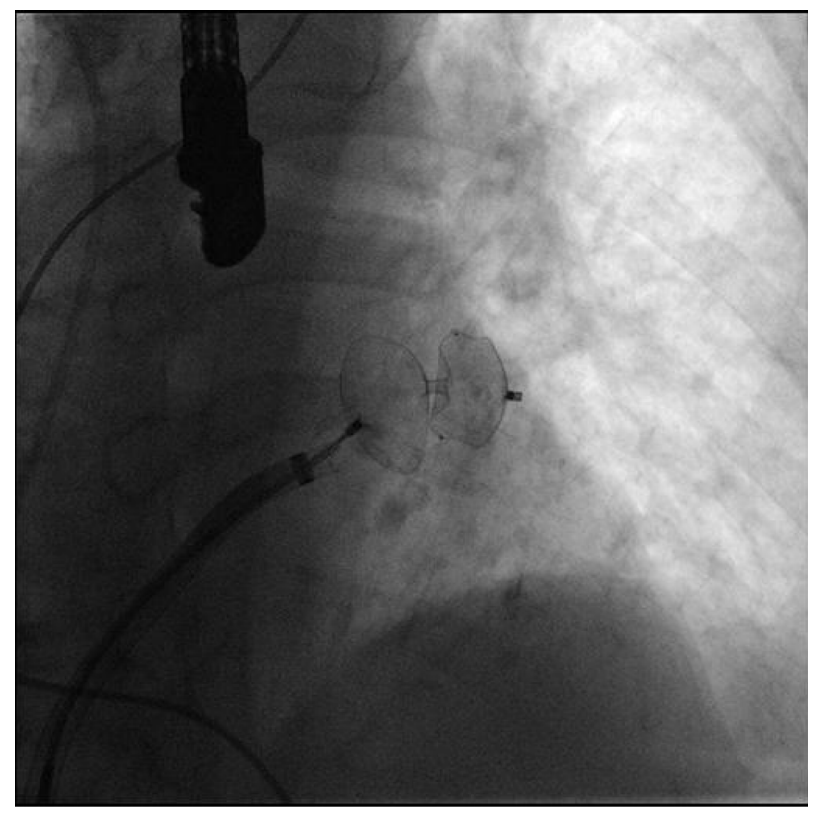

Figure 3 Fluoroscopic image of the final positioning steps of the Amplatzer cardiac plug device. 
therapy is recommended, followed by 5 months of ASA. The Initial European Experience by Park et $\mathrm{al}^{47}$ is a retrospective analysis of 143 patients who received the ACP device. Six patients were excluded because of difficult LAA anatomy or thrombus, and 137 procedures were attempted, of which 133 were successful (96\%). Ten patients (7\%) experienced complications: three periprocedural strokes, two device embolizations, five cardiac tamponades requiring pericardiocentesis, and four pericardial effusions with spontaneous resolution. Two transient episodes of myocardial ischemia resulting from air embolism were reported. The study showed the feasibility of LAA closure with the ACP device, as well as its relatively low rate of complications.

Lam et $a l^{48}$ reported 20 cases, of whom 19 (95\%) underwent successful implantation of the ACP device. They also reported one episode of transient myocardial ischemia and one esophageal lesion resulting from transesophageal echocardiography. No strokes were observed during a 12.7 month follow-up period compared with an estimated risk of $5.3 \%$.

Lòpez-Mìnguez et $\mathrm{al}^{49}$ recently published a trial of 35 patients treated with the ACP device. The implantation was successful in $97.14 \%$ of patients. No cardiac complications were observed, one femoral arteriovenous fistula was reported, and one severe gastrointestinal bleeding was observed, at which point clopidogrel was stopped and ASA alone was continued. Thrombus formation on the ACP surface was documented in five cases (14.28\%), and in four of them, enoxaparin was administered, with eventual thrombus resolution. During a 21-month follow-up period, only one TIA was observed in the patient who exhibited thrombus formation and did not receive enoxaparin. A transesophageal echocardiography performed in this patient showed three minor leaks at the border of the device.

Urena et $\mathrm{al}^{50}$ published a trial on 52 patients treated with the ACP device who demonstrated a contraindication to warfarin. The procedural success rate was 98.1\%. A single embolization was recorded, but the device was retrieved percutaneously. One patient experienced a TIA 24 hours after the procedure despite no visualized intracardiac thrombus and evidence of complete LAA sealing by transesophageal echocardiography. During a mean 20 months of follow-up, a lacunar stroke and second TIA were reported. Nevertheless, the number of strokes, thromboembolic events, and major bleeding events were significantly lower than expected based on $\mathrm{CHA}_{2} \mathrm{DS}_{2}$-VASc (congestive heart failure, hypertension, age 75 years or older, diabetes mellitus, prior stroke or TIA or thromboembolism, vascular disease, age 65 to 74 years, sex) and HAS-BLED (hypertension, abnormal renal/liver function, stroke, bleeding history or predisposition, labile international normalized ratio, elderly, drugs/alcohol concomitantly) score estimates. Peridevice residual leaks as assessed using transesophageal echo were observed in $16.2 \%$ of cases at 6 months; however, none of these patients experienced a stroke or TIA. Leaks were significantly associated with low ejection fractions, suggesting modification in LAA dimensions through remodeling can cause incomplete sealing. The lower rate of leaks using the ACP device as compared with that observed with the Watchman device is likely a result of the peculiar form of this device, which allows the disc to cover the LAA ostium, whereas the closure in the Watchman device is performed by positioning the device inside the LAA neck.

A recent systematic review ${ }^{51}$ evaluated the success and adverse event rates of percutaneous LAA device occlusion by combining 14 trials (1,737 patients). No distinction was made among individual devices despite combining trials, which evaluated the PLAATO, Watchman, or ACP devices. Overall, the authors concluded that LAA closure was successfully performed in $93 \%$ of cases with a $1.1 \%$ periprocedural mortality. Systemic embolism occurred in $1.6 \%$, cardiac perforation in $0.9 \%$, pericardial effusion and cardiac tamponade in $4 \%$, and device embolization in $0.7 \%$. Major bleeding occurred in $0.7 \%$ of patients. When the observed stroke incidence of eight trials was compared with the estimated stroke risk, as predicted from the $\mathrm{CHADS}_{2}$ score, an overall risk reduction of $1.9 \%-8.6 \%$ to $0 \%-3.8 \%$ was observed.

The newest Amplatzer Amulet (ACP-2) is the evolution of the original ACP device, a dedicated device for percutaneous LAA occlusion (Figure 4). The main design of the first

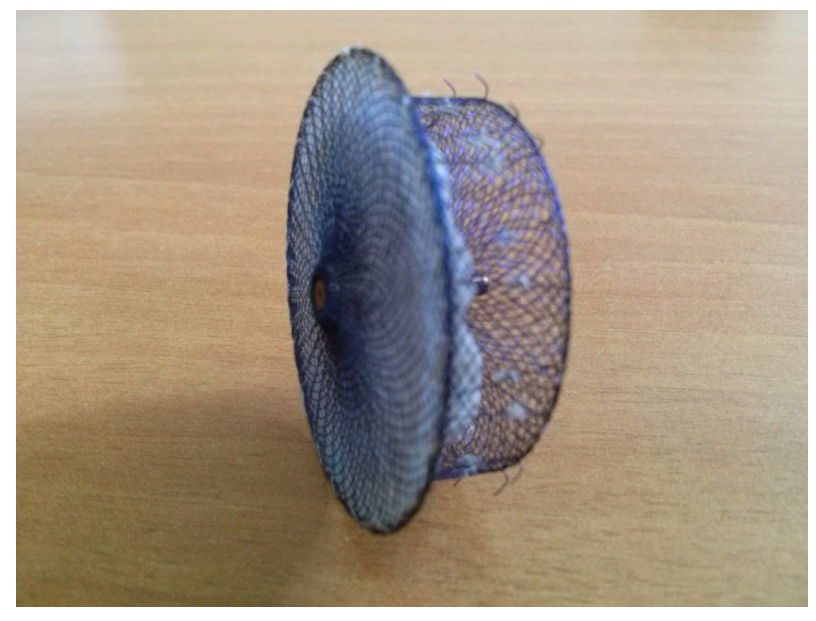

Figure 4 Amplatzer Amulet.

Notes: Note the increased length of the distal lobe and the diameter of the proxima disc. Note the amulet has the screw inside while the ACP has a screw through it. 
generation ACP-1 is maintained, although several features were modified to improve feasibility of implantation procedure and orifice sealing: the stabilizing wires are stiffer and the number is increased from six to ten pairs, larger sizes are available (31 and $34 \mathrm{~mm}$ ), the length of the distal lobe is increased by 2-3 $\mathrm{mm}$, and the diameter of the proximal disc was increased by $5.5-8 \mathrm{~mm}$. Freixa et al ${ }^{52}$ reported successful implantation in 24 of 25 patients with no periprocedural complications and no strokes at 3 months, suggesting feasibility and safety.

\section{Percutaneous LAA closure: epicardial approach}

Although most of the experience with LAA occlusion devices has been with endocardial devices, isolation of the LAA using an epicardial approach has more recently emerged as an attempt to simulate LAA closure with suture ligation during cardiac surgery. LAA occlusion with a percutaneous suture ligation method has been shown to be feasible for acute closure of the LAA and has been shown to result in LAA necrosis and atrophy. ${ }^{53}$ Endocardial suture ligation during cardiac surgery has been demonstrated to be incomplete in 10\%-30\% of patients, thus predisposing the patient to thromboembolic events. ${ }^{54,55}$ Potential reasons for incomplete closure include that the procedure is performed when the heart is in a flaccid state during cardiopulmonary bypass, that the access for suturing may be difficult, and that the success of LAA closure cannot be determined until the patient resumes cardiopulmonary bypass. These reasons may be mitigated by using a percutaneous epicardial approach without the need for cardiopulmonary bypass. Further, LAA isolation has been reported as a successful therapy for LAA tachycardias ${ }^{56}$ through electrical isolation and could allow elimination of focal LAA triggers that potentiate atrial tachycardias and AF. In addition, they offer further benefit because epicardial devices negate the need to implant a permanent endovascular device, as with the endocardial approach. The disadvantage with the epicardial approach is the need for pericardial access; patients who have had previous cardiac surgery are therefore not candidates for an epicardial device. There is also a percentage of the population that is not eligible for an epicardial occlusion device because of the unsuitable anatomy of the LAA.

At the present time, two device systems are available for use using an epicardial approach for LAA exclusion. The Aegis System is a percutaneous device that is positioned around the LAA to perform ligation. The system consists of an appendage grabber and a ligator. The most interesting aspect of this procedure is represented by an electrocardiogram-guided research of the LAA by the two electrodes mounted at the extremity of the grabber. Once the appendage is identified, a transesophageal echocardiogram or intracardiac ultrasound can be used to confirm the correct capture of the appendage. The second step of the procedure consists of ligating the appendage through a wire loop advanced over the grabber. In cases in which the appendage has multiple lobes, ligation can be performed in different positions. Results of this new approach are encouraging. ${ }^{57,58}$

The LARIAT ${ }^{\circledR}$ device is an LAA exclusion device that consists of a pretied suture enclosed in on a closed snare and that employs a hybrid endocardial-epicardial approach. Through a transseptal puncture, a magnetic probe is placed inside the LAA. Another magnetic probe is introduced in the pericardial space via a percutaneous epicardial approach. Over this endocardialepicardial magnetic wire bridge, a LARIAT ${ }^{\circledR}$ suture is inserted over the wire in the pericardial space to find the LAA and snare it. There is no requirement for anticoagulation or antiplatelet use after the procedure. Bartus et $\mathrm{al}^{59}$ first performed successful LAA exclusion using the LARIAT $^{\circledR}$ device in 13 patients: eleven with a closed-chest procedure and two during open-chest valvular cardiac surgery. A subsequent nonrandomized, singlecenter study ${ }^{60}$ evaluated a total of 119 patients for LAA ligation with the LARIAT $^{\circledR}$ device. Because of the thrombi within the LAA or unsuitable anatomy, only 89 patients (75\%) underwent LAA ligation. A 95\% success rate was reported, as assessed by transesophageal echocardiography. There were three procedurerelated complications (two of which were related to pericardial access and one to transseptal access). There were no device complications. There were no embolic strokes seen in the year of follow-up. Two deaths occurred more than 6 months after the procedure that were not related to the LARIAT $^{\circledR}$ device. Another small study published by Stone et $\mathrm{al}^{61}$ showed a success rate of $92.6 \%$ via a percutaneous LAA ligation approach with the SentreHeart LARIAT ${ }^{\circledR}$ snare device. All 27 patients were followed-up to 4 months. Periprocedural complications included one patient with LAA perforation, three patients developing pericarditis, and one patient having a stroke. On follow-up, stroke rate was $3.3 \%$.

In 2014, Han et $\mathrm{al}^{62}$ published a study on the effect of LAA ligation with the LARIAT $^{\circledR}$ device on LAA electrical activity. The trial included 68 patients with $100 \%$ procedural implantation success. Ninety-four percent of the patients had a reduction in the LAA voltage after the closure of the snare, with $33 \%$ of the patients having complete elimination of LAA voltage with the initial tightening of the suture. These preliminary results are interesting in the context in which LAA occlusion with this particular device may help decrease recurrence of atrial fibrillation in this patient population. 
Considering all these studies, one can state that the LAA occlusion procedure can be performed with the LARIAT $^{\circledR}$ device with high success rates and acceptably low access complications and adverse events, except pericarditis, which is reported in all studies using that device. Because this technique requires an epicardial approach, further research on device/suture material or adjuvant anti-inflammatory therapy that may reduce risk for pericarditis is required to improve procedural safety.

Risks from the catheter-based access of LAA occlusion also have their limitations. As mentioned in Table 1, many procedural complications have been noted with every device, including the PLAATO, Watchman, ACP, and LARIAT $^{\circledR}$ devices. It is encouraging to see, for example, in the PREVAIL study, that as this technique evolves, the rate of complications decreases. Nevertheless, its adverse outcomes are still nonnegligible.

\section{Current state of percutaneous LAA closure and future directions}

LAA closure is an intervention of increasing interest, in particular for patients with either contraindications to anticoagulation therapy, embolic events while receiving anticoagulation therapy, or intolerance to anticoagulants. Published trials demonstrate high overall success rates with favorable safety profiles compared with VKAs. LAA device closure has been recently been introduced into the 2012 focused update of the European Society of Cardiology as well as the 2014 American College of Cardiology/American Heart Association/Heart Rhythm Society guidelines for the management of AF in patients at high risk for embolic stroke and contraindication to long-term therapy with an oral anticoagulant, for which it has been given a class IIb recommendation for both. ${ }^{63,64}$ At this time, no evidence supports the systematic closure of LAA in patients with no contraindications to oral anticoagulants. Moreover, the advent of the NOAC will have a deep effect on the management of patients with nonvalvular AF and may further limit the indications for percutaneous LAA closure. Notably, no trials have been designed to compare NOACs with LAA closure or to evaluate the use of NOACs as adjunctive therapy in patients undergoing LAA closure. Furthermore, LAA occlusion with current devices does not obviate the need for long-term antithrombotic therapy with aspirin.

Percutaneous LAA closure can be associated with several procedural complications such as major bleeding, pericardial effusion, pericarditis, cardiac perforation, and air embolism. Moreover, the differences in LAA anatomy can increase the complexity of the procedure, posing challenges to accessing the LAA and sealing the LAA orifice.

Several device-related aspects still limit this approach, such as the high rate of incomplete LAA closure reported at long-term follow-up with transesophageal echocardiography and the occurrence of device embolization and migration. The Coherex Wave-crest is a new device for LAA closure furnished with anchoring points and the possibility of assessing device stability through a distal injection port during the procedure. Preliminary animal studies report durable LAA occlusion and an improved biocompatibility. ${ }^{65,66}$

Future refinements ofLAA occlusion technology are expected to improve the feasibility of the procedure. The device design and coating should aim to overcome the limitations of incomplete LAA orifice sealing and device dislodgement. In contrast, acute procedural complications have been shown to be influenced by a learning curve, and operator experience deeply affects outcomes of the procedure. ${ }^{67}$

The evolution and application of LAA closure in clinical practice will be related to an extensive knowledge of physiopathology of LAA and its effect on AF. Its has been shown that LAA is an alternative site for AF trigger, ${ }^{68}$ and as stated earlier, LAA closure has been linked to a reduction in recurrence of paroxysmal AF episodes. ${ }^{62}$ Moreover, hemodynamic consequences of LAA exclusion such as reduction in stroke volume and cardiac output have been amply documented. ${ }^{69}$

The occurrence of LAA thrombus increases in patients with AF and severe heart disease. ${ }^{29}$ The reduced ejection fraction and increased heart rate are a major determinant of the blood flow through the LAA and blood clot formation. Indications for LAA closure will depend on further studies to define subgroups of patients achieving maximal benefit from LAA exclusion.

\section{Disclosure}

VE is a recipient of a Clinician Scientist Award from the Canadian Institutes of Health Research. AT is proctor for St Jude Medical. PD is proctor for Gore \& Associates, St Jude Medical and Boston Scientific. The other authors have no conflicts of interest in this work.

\section{References}

1. Camm AJ, Kirchhof P, Lip GY, et al; European Heart Rhythm Association; European Association for Cardio-Thoracic Surgery. Guidelines for the management of atrial fibrillation: the Task Force for the Management of Atrial Fibrillation of the European Society of Cardiology (ESC). Eur Heart J. 2010;31(19):2369-2429. 
2. Sanna T, Diener HC, Passman RS, et al; CRYSTAL AF Investigators. Cryptogenic stroke and underlying atrial fibrillation. $N$ Engl $J$ Med. 2014;370(26):2478-2486.

3. Mohammed I, Mohmand-Borkowski A, Burke JF, Kowey PR. Stroke prevention in atrial fibrillation. $J$ Cardiovasc Med (Hagerstown). 2012;13(2):73-85.

4. Contractor T, Khasnis A. Left Atrial Appendage Closure in Atrial Fibrillation: A World without Anticoagulation? Cardiol Res Pract. 2011;2011:752808.

5. Hart RG, Pearce LA, Aguilar MI. Meta-analysis: antithrombotic therapy to prevent stroke in patients who have nonvalvular atrial fibrillation. Ann Intern Med. 2007;146(12):857-867.

6. Leithäuser B, Park JW. Cardioembolic stroke in atrial fibrillationrationale for preventive closure of the left atrial appendage. Korean Circ J. 2009;39(11):443-458.

7. Rash A, Downes T, Portner R, Yeo WW, Morgan N, Channer KS. A randomised controlled trial of warfarin versus aspirin for stroke prevention in octogenarians with atrial fibrillation (WASPO). Age Ageing. 2007;36(2):151-156.

8. Mant J, Hobbs FD, Fletcher K, et al; BAFTA investigators; Midland Research Practices Network (MidReC). Warfarin versus aspirin for stroke prevention in an elderly community population with atrial fibrillation (the Birmingham Atrial Fibrillation Treatment of the Aged Study, BAFTA): a randomised controlled trial. Lancet. 2007;370(9586):493-503.

9. Connolly SJ, Pogue J, Hart RG, et al; ACTIVE Investigators. Effect of clopidogrel added to aspirin in patients with atrial fibrillation. $N$ Engl J Med. 2009;360(20):2066-2078.

10. Connolly S, Pogue J, Hart R, et al; ACTIVE Writing Group of the ACTIVE Investigators. Clopidogrel plus aspirin versus oral anticoagulation for atrial fibrillation in the Atrial fibrillation Clopidogrel Trial with Irbesartan for prevention of Vascular Events (ACTIVE W): a randomised controlled trial. Lancet. 2006;367(9526):1903-1912.

11. Eikelboom JW, Wallentin L, Connolly SJ, et al. Risk of bleeding with 2 doses of dabigatran compared with warfarin in older and younger patients with atrial fibrillation: an analysis of the randomized evaluation of long-term anticoagulant therapy (RE-LY) trial. Circulation. 2011;123(21):2363-2372.

12. Patel MR, Mahaffey KW, Garg J, et al; ROCKET AF Investigators. Rivaroxaban versus warfarin in nonvalvular atrial fibrillation. $N$ Engl J Med. 2011;365(10):883-891.

13. Granger CB, Alexander JH, McMurray JJ, et al; ARISTOTLE Committees and Investigators. Apixaban versus warfarin in patients with atrial fibrillation. $N$ Engl J Med. 2011;365(11):981-992.

14. Giugliano RP, Ruff CT, Braunwald E, et al; ENGAGE AF-TIMI 48 Investigators. Edoxaban versus warfarin in patients with atrial fibrillation. N Engl J Med. 2013;369(22):2093-2104.

15. Galanis T, Thomson L, Palladino M, Merli GJ. New oral anticoagulants. J Thromb Thrombolysis. 2011;31(3):310-320.

16. Kwong JS, Lam YY, Yan BP, Yu CM. Bleeding of new oral anticoagulants for stroke prevention in atrial fibrillation: a meta-analysis of randomized controlled trials. Cardiovasc Drugs Ther. 2013;27(1):23-35.

17. Heidbuchel $\mathrm{H}$, Verhamme $P$, Alings $M$, et al. EHRA practical guide on the use of new oral anticoagulants in patients with non-valvular atrial fibrillation: executive summary. Eur Heart J. 2013;34(27):2094-2106.

18. Holster IL, Valkhoff VE, Kuipers EJ, Tjwa ET. New oral anticoagulants increase risk for gastrointestinal bleeding: a systematic review and meta-analysis. Gastroenterology. 2013;145(1):105-112.

19. Blackshear JL, Odell JA. Appendage obliteration to reduce stroke in cardiac surgical patients with atrial fibrillation. Ann Thorac Surg. 1996;61(2):755-759.

20. Sick PB, Schuler G, Hauptmann KE, et al. Initial worldwide experience with the WATCHMAN left atrial appendage system for stroke prevention in atrial fibrillation. J Am Coll Cardiol. 2007;49(13):1490-1495.

21. Whitlock RP, Healey JS, Connolly SJ. Left atrial appendage occlusion does not eliminate the need for warfarin. Circulation. 2009;120(19):1927-1932.
22. Douglas YL, Jongbloed MR, Gittenberger-de Groot AC, et al. Histology of vascular myocardial wall of left atrial body after pulmonary venous incorporation. Am J Cardiol. 2006;97(5):662-670.

23. Di Biase L, Santangeli P, Anselmino M, et al. Does the left atrial appendage morphology correlate with the risk of stroke in patients with atrial fibrillation? Results from a multicenter study. J Am Coll Cardiol. 2012;60(6):531-538

24. Al-Saady NM, Obel OA, Camm AJ. Left atrial appendage: structure, function, and role in thromboembolism. Heart. 1999;82(5):547-554.

25. Narumiya T, Sakamaki T, Sato Y, Kanmatsuse K. Relationship between left atrial appendage function and left atrial thrombus in patients with nonvalvular chronic atrial fibrillation and atrial flutter. Circ J. 2003;67(1):68-72.

26. Onalan O, Crystal E. Left atrial appendage exclusion for stroke prevention in patients with nonrheumatic atrial fibrillation. Stroke. 2007;38(2) (Suppl):624-630.

27. Bayard YL, Ostermayer SH, Hein R, et al. Percutaneous devices for stroke prevention. Cardiovasc Revasc Med. 2007;8(3):216-225.

28. Nakai T, Lesh MD, Gerstenfeld EP, Virmani R, Jones R, Lee RJ. Percutaneous left atrial appendage occlusion (PLAATO) for preventing cardioembolism: first experience in canine model. Circulation. 2002;105(18):2217-2222.

29. Sievert H, Lesh MD, Trepels T, et al. Percutaneous left atrial appendage transcatheter occlusion to prevent stroke in high-risk patients with atrial fibrillation: early clinical experience. Circulation. 2002;105(16):1887-1889.

30. Ostermayer SH, Reisman M, Kramer PH, et al. Percutaneous left atrial appendage transcatheter occlusion (PLAATO system) to prevent stroke in high-risk patients with non-rheumatic atrial fibrillation: results from the international multi-center feasibility trials. $\mathrm{J} \mathrm{Am} \mathrm{Coll} \mathrm{Cardiol}$. 2005;46(1):9-14.

31. Stöllberger C, Finsterer J, Schneider B. Does percutaneous closure of the left atrial appendage prevent stroke in atrial fibrillation? J Am Coll Cardiol. 4, 2006;47(7):1500.

32. Bayard YL, Omran H, Neuzil P, et al. PLAATO (Percutaneous Left Atrial Appendage Transcatheter Occlusion) for prevention of cardioembolic stroke in non-anticoagulation eligible atrial fibrillation patients: results from the European PLAATO study. EuroIntervention. 2010;6(2):220-226.

33. Gage BF, van Walraven C, Pearce $L$, et al. Selecting patients with atrial fibrillation for anticoagulation: stroke risk stratification in patients taking aspirin. Circulation. 2004;110(16):2287-2292.

34. Block PC, Burstein S, Casale PN, et al. Percutaneous left atrial appendage occlusion for patients in atrial fibrillation suboptimal for warfarin therapy: 5-year results of the PLAATO (Percutaneous Left Atrial Appendage Transcatheter Occlusion) Study. JACC Cardiovasc Interv. 2009;2(7):594-600.

35. Park JW, Leithäuser B, Gerk U, Vrsansky M, Jung F. Percutaneous left atrial appendage transcatheter occlusion (PLAATO) for stroke prevention in atrial fibrillation: 2-year outcomes. J Invasive Cardiol. 2009;21(9):446-450.

36. Ussia GP, Mulè M, Cammalleri V, et al. Percutaneous closure of left atrial appendage to prevent embolic events in high-risk patients with chronic atrial fibrillation. Catheter Cardiovasc Interv. 2009;74(2):217-222.

37. Leal S, Moreno R, de Sousa Almeida M, Silva JA, Lopez-Sendon JL. Evidence-based percutaneous closure of the left atrial appendage in patients with atrial fibrillation. Curr Cardiol Rev. 2012;8(1):37-42.

38. Holmes DR, Reddy VY, Turi ZG, et al; PROTECT AF Investigators. Percutaneous closure of the left atrial appendage versus warfarin therapy for prevention of stroke in patients with atrial fibrillation: a randomised non-inferiority trial. Lancet. 2009;374(9689):534-542.

39. Reddy VY, Doshi SK, Sievert H, et al; PROTECT AF Investigators. Percutaneous left atrial appendage closure for stroke prophylaxis in patients with atrial fibrillation: 2.3-Year Follow-up of the PROTECT AF (Watchman Left Atrial Appendage System for Embolic Protection in Patients with Atrial Fibrillation) Trial. Circulation. 2013;127(6):720-729. 
40. Bai R, Horton RP, DI Biase L, et al. Intraprocedural and long-term incomplete occlusion of the left atrial appendage following placement of the WATCHMAN device: a single center experience. J Cardiovasc Electrophysiol. 2012;23(5):455-461.

41. Viles-Gonzalez JF, Kar S, Douglas P, et al. The clinical impact of incomplete left atrial appendage closure with the Watchman Device in patients with atrial fibrillation: a PROTECT AF (Percutaneous Closure of the Left Atrial Appendage Versus Warfarin Therapy for Prevention of Stroke in Patients With Atrial Fibrillation) substudy. J Am Coll Cardiol. 2012;59(10):923-929.

42. Alli O, Doshi S, Kar S, et al. Quality of life assessment in the randomized PROTECT AF (Percutaneous Closure of the Left Atrial Appendage Versus Warfarin Therapy for Prevention of Stroke in Patients With Atrial Fibrillation) trial of patients at risk for stroke with nonvalvular atrial fibrillation. J Am Coll Cardiol. 2013;61(17):1790-1798.

43. Gangireddy SR, Halperin JL, Fuster V, Reddy VY. Percutaneous left atrial appendage closure for stroke prevention in patients with atrial fibrillation: an assessment of net clinical benefit. Eur Heart J. 2012;33(21):2700-2708.

44. Reddy VY, Möbius-Winkler S, Miller MA, et al. Left atrial appendage closure with the Watchman device in patients with a contraindication for oral anticoagulation: the ASAP study (ASA Plavix Feasibility Study With Watchman Left Atrial Appendage Closure Technology). J Am Coll Cardiol. 2013;61(25):2551-2556.

45. Maisel WH. Left atrial appendage occlusion - closure or just the beginning? N Engl J Med. 2009;360(25):2601-2603.

46. Holmes DR Jr, Kar S, Price MJ, et al. Prospective randomized evaluation of the Watchman Left Atrial Appendage Closure device in patients with atrial fibrillation versus long-term warfarin therapy: the PREVAIL trial. J Am Coll Cardiol. 2014;64(1):1-12.

47. Park JW, Bethencourt A, Sievert H, et al. Left atrial appendage closure with Amplatzer cardiac plug in atrial fibrillation: initial European experience. Catheter Cardiovasc Interv. 2011;77(5):700-706.

48. Lam YY, Yip GW, Yu CM, et al. Left atrial appendage closure with AMPLATZER cardiac plug for stroke prevention in atrial fibrillation: initial Asia-Pacific experience. Catheter Cardiovasc Interv. 2012;79(5):794-800.

49. Lopez-Minguez JR, Eldoayen-Gragera J, Gonzalez-Fernandez R, et al. Immediate and One-year Results in 35 Consecutive Patients After Closure of Left Atrial Appendage With the Amplatzer Cardiac Plug. Rev Esp Cardiol. 2013;66(2):90-97.

50. Urena M, Rodés-Cabau J, Freixa X, et al. Percutaneous left atrial appendage closure with the AMPLATZER cardiac plug device in patients with nonvalvular atrial fibrillation and contraindications to anticoagulation therapy. J Am Coll Cardiol. 2013;62(2):96-102.

51. Munkholm-Larsen S, Cao C, Yan TD, Pehrson S, Dixen U. Percutaneous atrial appendage occlusion for stroke prevention in patients with atrial fibrillation: a systematic review. Heart. 2012;98(12):900-907.

52. Freixa X, Abualsaud A, Chan J, et al. Left atrial appendage occlusion: initial experience with the Amplatzer ${ }^{\mathrm{TM}}$ Amulet $^{\mathrm{TM}}$. Int $J$ Cardiol. 2014;174(3):492-496.

53. Lee RJ, Bartus K, Yakubov SJ. Catheter-based left atrial appendage (LAA) ligation for the prevention of embolic events arising from the LAA: initial experience in a canine model. Circ Cardiovasc Interv. 2010;3(3):224-229.

54. Fisher DC, Tunick PA, Kronzon I. Large gradient across a partially ligated left atrial appendage. J Am Soc Echocardiogr. 1998;11(12):1163-1165.

55. Katz ES, Tsiamtsiouris T, Applebaum RM, Schwartzbard A, Tunick PA, Kronzon I. Surgical left atrial appendage ligation is frequently incomplete: a transesophageal echocardiograhic study. $J \mathrm{Am}$ Coll Cardiol. 2000;36(2):468-471.
56. Benussi S, Mazzone P, Maccabelli G, et al. Thoracoscopic appendage exclusion with an atriclip device as a solo treatment for focal atrial tachycardia. Circulation. 2011;123(14):1575-1578.

57. Bruce CJ, Stanton CM, Asirvatham SJ, et al. Percutaneous epicardial left atrial appendage closure: intermediate-term results. J Cardiovasc Electrophysiol. 2011;22(1):64-70.

58. Friedman PA, Asirvatham SJ, Dalegrave C, et al. Percutaneous epicardial left atrial appendage closure: preliminary results of an electrogram guided approach. J Cardiovasc Electrophysiol. 2009;20(8):908-915.

59. Bartus K, Bednarek J, Myc J, et al. Feasibility of closed-chest ligation of the left atrial appendage in humans. Heart Rhythm. 2011;8(2):188-193.

60. Bartus K, Han FT, Bednarek J, et al. Percutaneous left atrial appendage suture ligation using the LARIAT device in patients with atrial fibrillation: initial clinical experience. $J$ Am Coll Cardiol. 2013;62(2):108-118.

61. Stone D, Byrne T, Pershad A. Early Results With the LARIAT Device for Left Atrial Appendage Exclusion in Patients With Atrial Fibrillation at High Risk for Stroke and Anticoagulation. Catheter Cardiovasc Interv. 2013;n/a.

62. Han FT, Bartus K, Lakkireddy D, et al. The effects of LAA ligation on LAA electrical activity. Heart Rhythm. 2014;11(5):864-870.

63. Camm AJ, Lip GY, De Caterina R, et al; ESC Committee for Practice Guidelines (CPG). 2012 focused update of the ESC Guidelines for the management of atrial fibrillation: an update of the 2010 ESC Guidelines for the management of atrial fibrillation. Developed with the special contribution of the European Heart Rhythm Association. Eur Heart J. 2012;33(21):2719-2747.

64. January CT, Wann LS, Alpert JS, et al. 2014 AHA/ACC/HRS Guideline for the Management of Patients With Atrial Fibrillation: Executive Summary: A Report of the American College of Cardiology/American Heart Association Task Force on Practice Guidelines and the Heart Rhythm Society. J Am Coll Cardiol. Epub March 28, 2014.

65. Cheng Y, McGregor J, Edmiston D, et al. Long-term safety and biocompatibility of the Coherex WaveCrest ${ }^{\mathrm{TM}}$ left atrial appendage occluder in a canine model. J Am Coll Cardiol. 2014;63: doi:10.1016/ S0735-1097(14)61680-61686.

66. Cheng Y, McGregor J, Sommer R, et al. TCT-764 Safety and Biocompatibility of the Coherex WaveCrest ${ }^{\mathrm{TM}}$ Left Atrial Appendage Occluder in a 30-Day Canine Study. JAm Coll Cardiol. 2012;60(17_S): doi:10.1016/j. jacc.2012.08.807.

67. Reddy VY, Holmes D, Doshi SK, Neuzil P, Kar S. Safety of percutaneous left atrial appendage closure: results from the Watchman Left Atrial Appendage System for Embolic Protection in Patients with AF (PROTECT AF) clinical trial and the Continued Access Registry. Circulation. 2011;123(4):417-424.

68. Di Biase L, Burkhardt JD, Mohanty P, et al. Left atrial appendage: an underrecognized trigger site of atrial fibrillation. Circulation. 2010;122(2):109-118.

69. Stöllberger C, Schneider B, Finsterer J. Elimination of the left atrial appendage to prevent stroke or embolism? Anatomic, physiologic, and pathophysiologic considerations. Chest. 2003;124(6):2356-2362.

70. Meier B, Palacios I, Windecker S et al. Transcatheter left atrial appendage occlusion with Amplatzer devices to obviate anticoagulation in patients with atrial fibrillation. Catheter Cardiovasc Interv. $2003 ; 60(3): 417-422$. 


\section{Publish your work in this journal}

Medical Devices: Evidence and Research is an international, peerreviewed, open access journal that focuses on the evidence, technology, research, and expert opinion supporting the use and application of medical devices in the diagnosis, treatment and management of clinical conditions and physiological processes. The identification of novel

devices and optimal use of existing devices which will lead to improved clinical outcomes and more effective patient management and safety is a key feature. The manuscript management system is completely online and includes a quick and fair peer-review system. Visit http://www. dovepress.com/testimonials.php to read real quotes from authors.

Submit your manuscript here: http://www.dovepress.com/medical-devices-evidence-and-research-journal 